\title{
ANALISIS KEMAMPUAN PENGGUNA DALAM MENGGUNAKAN E-COMMERCE SHOPEE DENGAN METODE TECHNOLOGY ACCEPTANCE MODEL (TAM)
}

\author{
Delvy Chaniago ${ }^{1}$, Muhammad Akbar ${ }^{2}$ \\ ${ }^{1,2}$ Fakultas Ilmu Komputer, Universitas Bina Darma, Palemabang, 30264, Indonesia \\ E-mail: chaniagodelvy17@gmail.com ${ }^{1}$, muhamad.akbar@binadarma.ac.id ${ }^{2}$
}

\begin{abstract}
In 2009 Shopee is a platform electronic trading that was founded as the first market mobile-centric social where Shopee application users can shop, sell and explore anytime via smart phones safely and practically. Shopee application is influenced by several factors to produce a shopping system that fits the needs of its users, does not rule out the possibility that there are still users who feel disappointed with services Shopee, this is what makes the application users feel disappointed. in-depth measurement of which factors influence the attitude of acceptance of Shopee application among students. The research method uses exploratory with the number of respondents as many as 100 students. Data analysis techniques use technology acceptance models (TAM). The results showed that the factors Perceived usefulness, Perceived ease of use, Attitude, and Intention to use all had a significant effect on the acceptance of the use of Shopee applications among students. The overall test results producedR adjusted squares are by 0.550 or $55 \%$ with T value on Perceived ease of use on Attitude having a value of 7.861, Perceived ease of useof Perceived ease of use has a value of 9,777, Attitude to Intention to use has a value of 8,476 so that these results indicate that the T value is greater than the 5\% significance level and it can be concluded that the Perceived usefulness, Perceived ease of use, Attitude, and Intention to use mutual factors have a significant effect on Shopee application users among Students.
\end{abstract}

Keywords: TAM, Attitude, Perceived usefulness, Perceived ease of use, Intention to use, Shopee

\begin{abstract}
Abstrak
Pada tahun 2009 Shopee merupakan platform perdagangan elektronik yang didirikan sebagai pasar mobile-sentris sosial yang pertama dimana pengguna aplikasi Shopee ini dapat melakukan belanja, menjual, dan menjelajahi kapan saja melalui ponsel pintar dengan aman dan praktis. Aplikasi Shopee dipengaruhi dari beberapa faktor untuk menghasilkan sistem belanja yang sesuai dengan kebutuhan penggunanya, tidak menutup kemungkinan bahwa masih ada pengguna yang merasa dikecewakan dengan pelayanan Shopee, hal inilah yang membuat para pengguna aplikasi merasa dikecewakan.Untuk meningkatkan kemudahan dan kenyamanan pengguna sistem maka perlu adanya pengukuran yang mendalam mengenai faktor mana yang mempengaruhi sikap penerimaan pengguna aplikasi Shopee di kalangan Masyarakat. Metode penelitian menggunakan eksploratori dengan jumlah responden sebanyak 100 orang pengguna. Teknik analisis data menggunakan technology acceptance model (TAM). Hasil penelitian menunjukkan bahwa faktor Perceived usefulness, Perceived ease of use, Attitude, dan Intention to use semua berpengaruh signifikan pada penerimaan penggunaan aplikasi Shopee dikalangan Mahasiswa. Hasil pengujian secara keseluruhan yang dihasilkan R squares adjusted sebesar 0.550 atau 55\% dengan nilai T value pada Perceived ease of use terhadap Attitude memiliki nilai sebesar 7.861, Perceived ease of useterhadap Perceived ease of use memiliki nilai sebesar 9.777, Attitude terhadap Intention to use memiliki nilai sebesar 8.476 sehingga hasil ini menunjukkan bahwa nilai $\mathrm{T}$ value lebih besar dari taraf signifikansi 5\% dan dapat diambil kesimpulan bahwa faktor Perceived usefulness, Perceived ease of use, Attitude, dan Intention to use saling berpengaruh signifikan terhadap pengguna aplikasi Shopee di kalangan pengguna..
\end{abstract}

Kata Kunci: TAM, Sikap, Penerimaan Pengguna, Manfaat, Niat untuk digunakan, Shopee 


\section{Pendahuluan}

Perkembangan teknologi informasi selalu memliki pertumbuhan yang sangat pesat. Salah satunya adalah perkembangan internet yang telah menjadi alat komunikasi online yang sangat penting terutama di kalangan Masyarakat. Hal ini karena pengguna lebih cenderung tertarik terhadap segala sesuatu yang praktis, cepat, dan fleksibel. Banyak terdapat situs jual beli online seperti Bukalapak, JD.id, Tokopedia, Shopee, Lazada, dan masih banyak lagi. Dimana layanan jual beli online ini sudah menjadi konsep yang lazim dalam dunia internet. Konsumen lebih memilih media internet karena tidak perlu bertatap muka secara langsung dengan penyedia layanan. Penggunaan internet untuk aktifitas transaksi bisnis dikenal dengan istilah Electronic Commerce (e-commerce) atau perdagangan elektronik yang terdiri dari transaksi antara kedua belah pihak dengan melakukan pertukaran barang dan jasa dalam proses transaksi online. Peluang untuk berkembangnya transaksi perdagangan elektronik sangat terbuka di Indonesia. Hal tersebut dipengaruhi oleh faktor jumlah penduduk yang banyak sehingga menjadikan potensi pasar yang sangat luas .

Pada kalangan Masyarakat pemanfaatan media jual beli online dalam melakukan transaksi banyak diminati. Manfaat praktis dari transaksi online dianggap sebagai suatu keuntungan dari transakasi online, karena dapat membuat waktu bertransaksi menjadi lebih singkat. Hal ini merupakan salah satu faktor pendorong masyarakat untuk melakukan transkasi perdagangan elektronik. Pada penelitian ini digunakan platform aplikasi Shopee yang merupakan sebuah wadah belanja online berfokus pada platform mobile sehingga memudahkan pengguna untuk berbelanja dan berjualan langsung menggunakan ponsel. Aplikasi ini banyak menawarkan berbagai macam produk dengan kategori penjualan yaitu pakaian, elektronik, aksesoris, perlengkapan rumah tangga, dan lain sebagiannya. Selain itu juga kemudahan dalam memasukkan gambar produk yang akan dipasarkan dan maksimum hingga 9 gambar dapat di-upload secara bersamaan. Pada bagian penjualan terdapat fitur yang akan mempermudah penjual ketika menunggu pembayaran sebelum produk dikirim, hingga status transaksi yang sudah selesai. Layanan yang terdapat pada aplikasi Shoope diantaranya pengiriman yang sudah terintegrasi dan banyak fitur sosial yang inovatif dengan menerapkan sistem layanan jual beli interaktif antara penjual dan pembeli melalui fitur live chat dan juga menyediakan fitur hastag yang memungkinkan pengguna untuk mengikuti trend terbaru secara mudah. Kemudian para pengguna Shopee juga akan menerima update secara realtime.

Shopee Indonesia mencatat pada akhir 2017 terdapat 25 juta pengunduh. Sedangkan jumlah mitra penjual Shopee sebanyak satu juta orang per 31 oktober 2017. Hal tersebut tidak menutup kemungkinan masih ada pengguna yang merasa dikecewakan dengan pelayanan Shopee. Meskipun jumlah pengunduhnya sudah banyak. Rasa kecewa dari pengguna bisa disebabkan oleh kurang responsifnya penjual kepada para pembeli ketika sudah melakukan pembayaran dan barang yang dibeli tidak sesuai dengan spesifikasi yang tertera pada aplikasi Shopee. Kemudian ada juga yang melakukan pengembalian uang namun tidak segera masuk ke dalam koin Shopee bahkan sampai pengembalian uang tersebut tidak diproses oleh para pembeli. Hal ini membuat para pengguna aplikasi merasa dikecewakan, namun di sisi lain banyak pula pengguna yang memberikan kesan positif pada aplikasi tersebut diantaranya adalah bebas biaya pengiriman, terdapat potongan harga dan juga dapat membeli barang dengan mudah. Penelitian ini diperlukan untuk mengetahui faktor-faktor yang dapat mempengaruhi penerimaan pengguna dalam transaksi online pada Shopee di kalangan masyarakat.

Konsep dari penelitian ini menggunakan model penerimaan teknologi atau Technology Acceptance Model (TAM), model ini menyebutkan bahwa pengguna akan lebih cenderung menggunakan sistem apabila sistem tersebut mudah digunakan dan bermanfaat bagi penggunanya, dengan metode Technology Acceptance Model (TAM) maka dapat digunakan untuk mendeskripsikan dan memperkirakan penerimaan terhadap penggunaan suatu sistem atau aplikasi, metode ini mempunyai dasar-dasar untuk mengetahui faktor yang mempengaruhi penerimaan terhadap suatu sistem, kemudian menjelaskan juga bagaimana hubungan sebab akibat yang berhubungan dengan manfaat suatu system informasi dan kemudahan dalam penggunaannya. Metode ini juga menunjukkan bagaimana pengguna dapat menerima dan menggunakan sebuah teknologi baru dengan sejumlah faktor yang mempengaruhi keputusan pengguna untuk memutuskan bagaimana dan kapan pengguna akan menggunakan sistem atau aplikasitersebut. Dari 
masalah inilah muncul penelitian yang diperlukan untuk dapat mengetahui faktor-faktor mempengaruhi penerimaan penggunaan aplikasi Shopee di kalangan Masyarakat dengan menggunakan teori Technology Acceptance Model (TAM) ada beberapa variabel yang dapat digunakan dalam teori tersebut. Namun peneliti di sini akan menggunakan 4 variabel di antaranya yaitu; 1). Perceived Usefulness, 2). Perceived ease of use, 3). Attitude, 4). Intention to use dengan menggunakan (Partial Least Square) PLS. Hasil dari penelitian ini diharapkan dapat meningkatkan kualitas pelayanan pada aplikasi Shopee dengan mengetahui faktor-faktor yang mempengaruhinya tersebut dan pengguna dapat dengan nyaman, aman dan mudah dalam menggunakannya

\section{Metodologi Penelitian}

\subsection{Sejarah Shopee}

Shopee merupakan platform perdagangan elektronik yang didirikan pada tahun 2009 sebagai pasar mobilesentris sosial yang pertama dimana pengguna aplikasi Shopee ini dapat melakukan belanja, menjual, dan menjelajahi kapan saja melalui ponsel pintar dengan aman dan praktis. Aplikasi Shopee dimulai dengan model bisnis pasar pelanggan untuk pelanggan (costumer to customer) kemudian telah beralih menjadi model hibrid dengan mode $C 2 C$ dan $B 2 B$ (bisnis to bisnis) dikarenakan adanya perkembangan baru dengan membuka Shopee Mall yang merupakan platform toko dalam jaringan untuk pendistribusian brand ternama. Pada penelitian ini, menggunakan menggunakan referensi dari penelitian sebelumnya, yaitu penelitian dari Wahyuningsuara dan Rokhmawati yang mengemukakan tentang faktor-faktor yang mempengaruhi penerimaan pengguna dalam transaksi online pada Shopee" variabel yang digunakan pada penelitian ini adalah Intention to Transact, Trust, Perceived Usefulness, Perceived risk, Perceived ease of use, Satisfaction With Past On-Line, Actual Transaction menggunakan (Partial Least Square) PLS, dengan hasil Intention to Transact mempengaruhi Actual Transaction yang berhubungan secara signifikan, Trust dengan Intention to Transact tidak mempengaruhi dan tidak berhubungan secara signifikan, perceived ease of use mempengaruhi Intention to Transact dan berhubungan secara signifikan, perceived ease of use tidak mempengaruhi dan tidak berhubungan secara signifikan terhadap Intention to Transact, perceived ease of use mempengaruhi dan berhubungan signifikan perceived usefulness, perceived risk tidak mempengaruhi dan tidak berhubungan signifikan terhadap intention to transact, trust mempengaruhi dan berhubungan signifikan terhadap perceived usefulness, trust mempengaruhi dan berhubungan signifikan perceived ease of use, trust mempengaruhi dan berhubungan signifikan dengan perceived risk, satisfaction with past online transaction mempengaruhi dan berhubungan secara signifikan dengan trust.

\subsection{Analisis}

Menurut Spradley (Sugiyono, 2015:335) mengatakan bahwa analisis adalah sebuah kegiatan untuk mencari suatu pola selain itu analisis merupakan cara berpikir yang berkaitan dengan pengujian secara sistematis terhadap sesuatu untuk menentukan bagian, hubungan antar bagian dan hubungannya dengan keseluruhan. Analisis adalah suatu usaha untuk mengurai suatu masalah atau fokus kajian menjadi bagianbagian (decomposition) sehingga susunan/tatanan bentuk sesuatu yang diurai itu tampak dengan jelas dan karenanya bisa secara lebih terang ditangkap maknanya atau lebih jernih dimengerti duduk perkaranya (Satori dan Komariyah, 2014:200). Nasution dalam Sugiyono (2015:334) melakukan analisis adalah pekerjaan sulit, memerlukan kerja keras. Tidak ada cara tertentu yang dapat diikuti untuk mengadakan analisis, sehingga setiap peneliti harus mencari sendiri metode yang dirasakan cocok dengan sifat penelitiannya. Bahan yang sama bisa diklasifikasikan berbeda. Jadi dapat ditarik kesimpulan bahwa analisis merupakan penguraian suatu pokok secara sistematis dalam menentukan bagian, hubungan antar bagian serta hubungannya secara menyeluruh untuk memperoleh pengertian dan pemahaman yang tepat. Data yang dimaksud dalam penelitian ini adalah hasil tes kecerdasan emosional berdasarkan teori Goleman yang dapat mengidentifikasi tingkat kecerdasan emosional siswa dengan tingkat kecerdasan emosional tinggi, siswa dengan tingkat kecerdasan emosional sedang, dan siswa dengan tingkat kecerdasan emosional rendah, tes kemampuan pemecahan masalah matematika berupa soal uraian/essay untuk melihat kemampuan pemecahan masalah matematika berdasarkan tahapan Wallas, serta wawancara terhadap subjek untuk mengidentifikasi kemampuan berpikir kreatif siswa dalam memecahkan masalah matematika. 


\subsection{E-Commerce}

Menurut Undang- Undang No. 20 Tahun 2003 Pendidikan adalah usaha sadar dan terencana untuk mewujudkan suasana belajar dan proses pembelajaran agar peserta didik secara aktif mengembangkan potensi dirinya untuk memiliki kekuatan spiritual keagamaan, pengendalian diri, kepribadian, kecerdasan, akhlak mulia, serta ketrampilan yang diperlukan dirinya, masyarakat, bangsa dan negara. Perdagangan sebenarnya merupakan kegiatan yang dilakukan manusia sejak awal peradabannya. Sejalan dengan perkembagan manusia, cara dan sarana yang digunakan untuk berdagang senantiasa berubah. Bentuk perdagangan terbaru yang kian memudahkan penggunanya kini ialah e-commerce. Dengan adanya $e$ commerce ini, memungkinkan adanya transaksi as-salam yaitu: merupakan bentuk transaksi dengan sistem pembayaran secara tunai atau disegerakan tetapi penyerahan barang ditangguhkan dan transaksi al-istina yaitu: merupakan bentuk transaksi dengan sistem pembayaran secara disegerakan atau secara ditangguhkan sesuai kesepakatan dan penyerahan barang ditangguhkan. Transaksi as-salam disebut juga as-salaf, dalam hal ini merupakan suatu bentuk keringanan dalam bermuamalah dan memberikan kemudahan kepada manusia dalam berinteraksi dengan sama, khususnya pada maslah pertukaran harta, seperti halnya jual beli dengan hutang (Asnawi, 2008). Transaksi as-salam dibolehkan Al-Qur'an dan AsSunnah. Oleh karena itu ketika Rasullah saw tiba di Madinah, orang-orang menggunakan jaringanjaringan komputer (computer networks) yaitu internet (Berkatulloh dan prasetyo, 2005). Dengan kata lain e-commerce adalah merupakan suatu transaksi komersial yang dilakukan antara penjual dan pembeli atau dengan pihak lain dalam hubungan perjanjian yang sama untuk mengirimkan sejumlah barang, pelayanan, atau perahlian hak (Ding dalam Berkatullah dan Prasetyo, 2005). Dalam pengertian lain e-commerce adalah pembelian dan penjualan, pemasaran dan pelayanan serta pengiriman dan pembayaran produk, jasa dan informasi di internet dan jaringan lainnya, antara perusahaan berjaringan dengan pelanggan, pemasok, dan mitra bisnis lainya (Humdiana dan Indriyani, 2005).

\subsection{Partial Least Square / PLS}

Partial least square atau yang biasa disingkat PLS adalah jenis analisis statistik yang kegunaannya mirip dengan SEM di dalam analisis covariance. Oleh karena mirip SEM maka kerangka dasar dalam PLS yang digunakan adalah berbasis regresi linear. Jadi apa yang ada dalam regresi linear, juga ada dalam PLS. Hanya saja diberi simbol, lambang atau istilah yang berbeda. Dalam bahasan tentang PLS, tentunya tidak akan cukup hanya dalam satu artikel. Maka kami akan buat dalam serangkaian artikel, yang cara penyampaiannya kami upayakan sederhana dan mudah dipahami serta berbasis studi kasus atau contoh langsung pengoperasiannya dalam software misal smartPLS. Partial least square adalah suatu teknik statistik multivariat yang bisa untuk menangani banyak variabel respon serta variabel eksplanatori sekaligus. Analisis ini merupakan alternatif yang baik untuk metode analisis regresi berganda dan regresi komponen utama, karena metode ini bersifat lebih robust atau kebal. Robust artinya parameter model tidak banyak berubah ketika sampel baru diambil dari total populasi (Geladi dan Kowalski, 1986). Partial Least Square suatu teknik prediktif yang bisa menangani banyak variabel independen, bahkan sekalipun terjadi multikolinieritas diantara variabel-variabel tersebut (Ramzan dan Khan, 2010).

Menurut Wold, PLS adalah metode analisis yang powerfull sebab tidak didasarkan pada banyak asumsi atau syarat, seperti uji normalitas dan multikolinearitas. Metode tersebut mempunyai keunggulan tersendiri antara lain: data tidaklah harus berdistribusi normal multivariate. Bahkan indikator dengan skala data kategori, ordinal, interval sampai rasio dapat digunakan. Keunggulan lainnya adalah ukuran sampel yang tidak harus besar. PLS pertama kali dikembangkan oleh Herman O. A. Wold dalam bidang ekonometrik pada tahun 1960-an. Kelebihan dari Partial Least Square yang penting adalah dapat menangani banyak variabel independen, bahkan meskipun terjadi multikolinieritas diantara variabelvariabel independen. Analisis regresi berganda sebenarnya masih dapat digunakan ketika terdapat variabel prediktor yang banyak. Namun, jika jumlah variabel tersebut terlalu besar (misal lebih banyak variabel dari pada jumlah observasi), maka akan diperoleh model yang fit dengan data sampel, tapi akan gagal memprediksi untuk data baru. Fenomena ini disebut overfitting. Dalam kasus overfitting seperti itu, meskipun terdapat banyak faktor manifes, mungkin saja hanya terdapat sedikit faktor laten yang paling bisa menjelaskan variasi dalam respon. Maka muncullah ide PLS. Ide umum dari PLS adalah untuk mengekstrak faktor-faktor laten tersebut, yang menjelaskan sebanyak mungkin variasi faktor manifes saat memodelkan variabel respon. Walaupun Partial Least Square digunakan untuk menkonfirmasi teori, tetapi 
dapat juga digunakan untuk menjelaskan ada atau tidaknya hubungan antara variabel laten. Partial Least Square dapat menganalisis sekaligus konstruk yang dibentuk dengan indikator refleksif dan indikator formatif dan hal ini tidak mungkin dijalankan dalam Structural Equation Model (SEM) karena akan terjadi unidentified model.

\subsection{Metode Penelitian}

Berkaitan dengan penjelasan di atas, maka diperlukan untuk mengetahui perilaku penggunaan dalam online shopping yaitu pada aplikasi Shopee dengan menggunakan teori technology acceptance model (TAM) menurut APPENDIX, ada 4 operasional variabel yang digunakan pada penelitian ini adalah 1). Perceived Usefulness, 2). Perceived ease of use, 3). Attitude, dan 4). Intention to use dengan menggunakan (Partial Least Square) PLS.

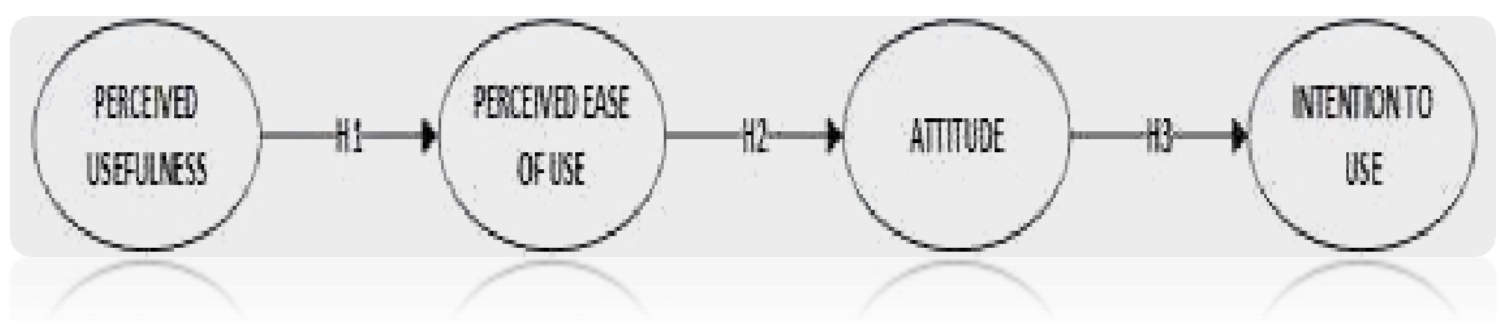

Gambar 3.1 Hipotesis technology acceptance model pada aplikasi Shopee

Berdasarkan pada kajian teori maka hipotesis pada penelitian ini adalah sebagai berikut;

H1 Terdapat pengaruh signifikan atas perceived Usefulness terhadap Perceived Ease of use pada aplikasi Shopee di kalangan pengguna.

H2 Terdapat pengaruh signifikan atas Perceived ease of use terhadap Attitude pada Aplikasi Shopee di kalangan pengguna.

H3 Terdapat pengaruh signifikan atas Attitude terhadap Intention to use pada E- Commerce Shopee di kalangan Masyarakat. Metode penelitian yang digunakan adalah metode deskriptif exploratory, dimana pada penelitian ini melakukan analisis hubungan -hubungan antara satu variabel dengan varaibel lainnya atau dimana suatu variabel dapat menerangkan hubungan, menguji hipotesis dan membuat prediksi. Teknik pengambilan sampel pada penelitian ini menggunakan quota sampling terhadap para pengguna aplikasi Shopee. Dengan responden sebanyak 50 orang dan dengan kriteria pernah melakukan transaksi pada aplikasi Shopee selama enam bulan terakhir. Selain itu pada penelitian ini dalam penyusunan kuesioner menggunakan teknik teori, total item pertanyaan sebanyak 14 item. Kemudian dengan mengukur validitas dari isi kuesioner (content validity) dan menghitung penilaian tersebut menggunakan formula dari Aiken's.

Pengumpulan data disebar secara online dan langsung kepada seluruh Masyarakat yang berada di wilayah Palembang dan Sekitarnya, kemudianuntuk penentuan sample didasarkan oleh beberapa kriteria:

1) Bersedia untuk mengisi kuesioner yang disebarkan oleh peneliti,

2) Pernah belanja online di aplikasi Shopee. Setelah menyebar kuesioner maka data yang diperoleh kemudian diolah menggunakan Smart PLS.

3). Hasil data yang diolah kemudian dianalisis hubungan antar variabel yang telah dihipotesiskan apakah signifikan dan diterima atau ditolak. . Pengolahan data yang diperoleh menggunakan Partial Least Squares (PLS) dilakukan untuk melakukan pengukuran prediksi yang mempunyai sifat nonparametik melalui convergent-validity yang dimana ukuran reflektif individual berkolerasi dengan nilai loading $>0.50$. 


\section{Hasil Dan Pembahasan}

\subsection{Hasil Output Smart PLS 3}

1). Pada hasil perhitungan Discriminant Validity diperoleh berdasarkan pada Fornell- Lacker yang bisa dilihat pada Tabel 1:

Tabel 1. Hasil perhitungan discriminant validity

\begin{tabular}{|c|c|c|c|c|}
\hline & Attitude (C) & Ittention To Use (D) & Perceived Ease Of Use (B) & Perceived Usefulness (A) \\
\hline Attitude (C) & 0.635 & & & \\
\hline Ittention To Use (D) & -0.501 & 0.734 & & \\
\hline Perceived Ease Of Use (B) & -0.652 & 0.084 & 0.638 & \\
\hline Perceived Usefulness (A) & -0.370 & 0.202 & 0.540 & 0.586 \\
\hline
\end{tabular}

Dan average variance extracted (AVE) Dari Tabel 2 didapatkan hasil P Pengguna kecuali untuk variable Intention to use menunjukan nilai AVE 0.539 artinya tidak berpengaruh signifikan di kalangan pengguna. Value average variance extracted (AVE) yang menunjukkan bahwa variabel Attitude, Perceived Usefulness, dan Perceived ease of use kurang dari 0.05 atau 5\% maka variabel berpengaruh signifikan terhadap penggunaan aplikasi Shopee di kalangan .

Tabel 2. Hasil perhitungan average variance extracted (AVE)

\begin{tabular}{|lcccc|}
\hline Attitude (C) & 0.240 & 0.249 & 0.666 & 0.404 \\
\hline Ittention To Use (D) & 0.040 & 0.757 & 0.584 & 0.539 \\
\hline Perceived Ease Of Use (B) & -0.010 & 0.606 & 0.095 & 0.407 \\
\hline Perceived Usefulness (A) & 0.428 & 0.576 & 0.520 & 0.344 \\
\hline
\end{tabular}

2). Adapun hasil Path analysis dan uji signifikasi dengan melakukan perhitungan nilai Path Coefficient dan pengambilan keputusan seperti pada Tabel 3:

Tabel 3. Nilai path coefficient

\begin{tabular}{|c|c|c|c|c|}
\hline & Attitude $(\mathrm{C})$ & Ittention To Us.... & Perceived Ease.... & Perceived Usef... \\
\hline Attitude (C) & & -0.501 & & \\
\hline \multicolumn{5}{|l|}{ Ittention To Use (D) } \\
\hline Perceived Ease Of Use (B) & -0.652 & & & \\
\hline Perceived Usefulness (A) & & & 0.540 & \\
\hline
\end{tabular}

3). Berdasarkan pada pengolahan data dengan menggunakan software SmartPLS diperoleh model seperti pada Gambar 4:

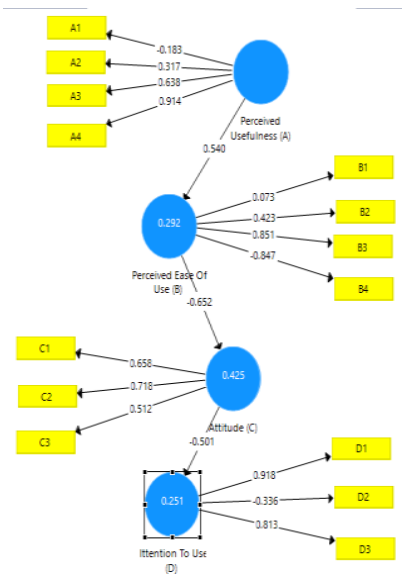

Gambar 1. Path technology acceptance model 
Berdasarkan pada perhitungan dan pengeolahan data dengan menggunakan software SmartPLS di atas memiliki sebagai berikut:

1. H1 Perceived Usefulness terhadap Perceived ease of use mempunyai hasil signifikan sebesar 0.540 sehingga faktor perceived Usefulnesss berpengaruh signifikan terhadap Perceived ease of use pada aplikasi Shopee di kalangan Pengguna Shopee

2. H2 Perceived ease of use terhadap Attitude mempunyai hasil minimum sebesar -0.652 sehingga faktor Perceived ease of use tidak berpengaruh signifikan terhadap Atitude pada Aplikasi Shopee di kalangan Pengguna.

3. H3 Attitude terhadap Intention to use mempunyai hasil minimum sebesar -0.501 sehingga faktor Attitude tidak berpengaruh signifikan terhadap Intention to use pada Aplikasi Shopee di kalangan Pengguna.

Hasil penelitian menunjukkan bahwa terdapat faktor yang tidak signifikan, sedangkan variabel lainnya memiliki hasil signifikan terhadap pengguna Aplikasi Shopee di kalangan Masyarakat. Akan tetapi hasil pengujian secara keseluruhan yang dihasilkan $\mathrm{R}$ squares adjusted sebesar 0.925 atau $92 \%$ dengan nilai $\mathrm{T}$ value pada Perceived usefulness terhadap Attitude memiliki nilai sebesar -0.352, Perceived usefulness terhadap Ittention To Use memiliki nilai sebesar 0.176, Perceived usefulness terhadap Perceived ease of use memiliki nilai sebesar 0.540, Perceived ease of use terhadap Ittention To Use memiliki nilai sebesar 0.326, Attitude terhadap Ittention To Use memiliki nilai sebesar -0.501.

Sehingga hasil ini menunjukkan bahwa nilai $\mathrm{T}$ value lebih besar dari taraf signifikansi 5\% dan dapat diambil kesimpulan bahwa faktor Intention to use, Perceived ease of use, Attitude mempengaruhi Perceived usefulness pada Aplikasi Shopee di kalangan Pengguna.

\section{$4 \quad$ Kesimpulan}

Kemampuan keberhasilan dalam penerimaan penggunaan aplikasi Shopee sangat bergantung dari para pengguna dan perilaku atas penggunaan sistem tersebut. Penelitian ini membuktikan bahwa manfaat penggunaan, kemudahan penggunaan, sikap dan niat penggunaan aplikasi Shopee berpengaruh terhadap penerimaan penggunaan aplikasi Shopee di kalangan Masyarakat. Dengan demikian dapat disimpulkan bahwa faktor Perceived ease of use, Attitude, dan Intention to use berpengaruh signifikan pada penerimaan penggunaan aplikasi Shopee. Sedangkan untuk Perceived usefulness tidak berpengaruh terhadap penerimaan aplikasi shopee tersebut.Agar penggunaan aplikasi Shopee dapat berhasil dengan optimal maka disarankan agar menjaga dan meningkatkan kualitas pelayanan pada aplikasi tersebut.

Dalam pengerjaan skripsi ini tentu masih banyak kekurangan yang masih perlu dan harus dipelajari. Perlu ada kajian lebih lanjut dengan memasukkan beberapa variabel lain yang diduga berpengaruh terhadap penerimaan penggunaan aplikasi Shopee di kalangan Pengguna seperti faktor gender, demografi dan kompleksitas dari aplikasi Shopee, sehingga dapat menghasilkan gambaran hasil penelitian yang lebih komprehensif lagi Pada halaman awal aplikasi Shopee banyak konten yang ditampilkan sehingga membuat pengguna mengalami kesulitan mengakses diharapkan dapat meminimalisirkan konten ataupun iklan yang ditampilkan sehingga dapat memudahkan pengguna untuk mengakses dan mencari kebutuhan pada E-Commerce Shopee.

\section{Daftar Pustaka}

C. D. T. Wahyuningsuara, R. I. Rokhmawati, and N. H. Wardani, “Analisis Faktor- Faktor Yang Mempengaruhi Penerimaan Pengguna Dalam Transaksi Online Pada Shopee,” vol. 2, no. 9, 2018.

I.Puspaningtiyas, “ANALISIS FAKTOR- FAKTOR YANG MEMPENGARU HIMINAT PERIL AKU TERHADAP PENGGUNAAN SISTEM INFORMASI AKUNTANSI BERBASIS E-COMMERCE," 2016. 
R. H. Walker, M. C. Robert, H. Heather, R. H. Walker, M. C. Robert, and H.Heather, "International Journal of Service Industry Management Article information: To cite this document :,"2006.

Kusuma and U. I. Indonesia,"Membangun Kembali Kepercayaan Masyarakat Pasca Pelanggaran dalam Business to Consumer ( B2C ) E-Commerce: Studi Empiris di Yogyakarta," no. January, 2016.

A. Defranc et al., "Measuring oral health behaviour in Flemish health care workers: An application of the theory of planned behaviour," Community Dent. Health, vol. 25, no. 2, pp. 107-114, 2008.

Persepsi Manfaat dan Persepsi Kemudahan terhadap Sikap serta dampeknya atas pengguna ulang online shopping pada e-Commerce," J. Comput. Bisnis, vol. 8, no. 2, pp. 92- 100, 2014.

M. Walfajri, “E-Commerce Shopee Bersiap Rilis Shopee Pay,” 2018.I. Sidharta and R. Sidh, "Pengukuran

Aina, "Kelebihan dan Kekurangan Shopee," 2016. [Online]. Available: https://portaluang.com/2016/12/mengenal-kelebihan-dan-kekurangan-Shopee.html. [Accessed:25- Feb-2019]. 